\title{
Bebidas tradicionales y ancestrales del Caribe colombiano*
}

\section{Colombia's Caribbean coast ancestral and traditional drinks}

\author{
JEAN PIERRE RÍOS ROJAS \\ https://orcid.org/0000-0002-1986-0452 (10)
}

\section{Artículo de investigación}

Recepción: 30 de abril de 2020

Aceptación: 25 de mayo de 2020

\section{Cómo citar este artículo}

Ríos Rojas, J. 2020). Bebidas tradicionales y ancestrales del Caribe colombiano. Sosquua. Revista Especializada en Gastronomía 2(1), pp. 48-56 Recuperado a partir de: http:// cipres.sanmateo.edu.co/index.php/sosquua

Reconocimiento-SinObraDerivada 4.0 Internacional (CC BY-NC-ND)

\footnotetext{
*El autor agradece a Paula Andrea Carreño Deaza y Juan Diego León Fuccz, estudiantes en el programa de gastronomía de la Fundación Universitaria San Mateo (Bogotá), quienes colaboraron en la ejecución del proyecto de investigación.

${ }^{4}$ Docente investigador, Fundación Universitaria San Mateo. Correo electrónico: jprios@sanmateo. edu.co
} 


\section{Resumen}

En el área de la gastronomía, a lo largo de la experiencia profesional se ha evidenciado que, cuando los profesionales en el área culinaria tratan de establecer la importancia de enaltecer las tradiciones del país, se centran en el desarrollo de la cocina; dejan de lado las preparaciones de bebidas ancestrales. La presente indagación analiza las bebidas nativas de la región del Caribe, las enmarca a nivel cultural, social y geográfico. Utiliza herramientas de recolección de información sobre el conocimiento de preparación dentro del sector de restaurantes de la capital, con personas procedentes de la región. Así, es posible identificar los temas de formación para el desarrollo del gastrónomo colombiano.

Palabras clave: : bebida; tradición; patrimonio cultural.

\section{Abstract}

Throughout the professional experience in the gastronomy area, it is evidence that when professionals in the culinary area try to establish the importance of enhancing the country's traditions; it focuses on the cuisine development, leaving aside the ancestral drink preparations. This investigation analyzes the Colombia's Caribbean region native drinks, framing them at a cultural, social and geographic level. It uses tools to collect information on preparation knowledge within the restaurant sector of the capital, and with people from the region. It identifies the training topics for the development of the Colombian gourmet.

Keywords: drink; tradition; cultural heritage. 


\section{Introducción}

La investigación evidencia que los colombianos carecen del sentido de pertinencia del patrimonio cultural de las regiones nacionales, tal vez por la falta de conocimiento de las preparaciones ancestrales. Esta desinformación se puede evidenciar de manera tangible cuando se toma como eje central de discusión las bebidas autóctonas. Dentro de las consultas realizadas en la indagación se toma como referencia al guarapo y la chicha como eje representativo de la cultura nacional.

Ahora bien, en la cultura del Caribe existe un sin número de preparaciones centradas en el desarrollo de elementos ceremoniales. Establecen un elemento socio-cultural entre lo divino y lo humano. Según el Ministerio de Cultura (2013).

[...] la Política de Salvaguardia del Patrimonio Cultural Inmaterial en Colombia, el campo de acción está delimitada a 12 temas, uno de ellos se denomina Cultura Culinaria en el cual es fundamental desarrollar elementos que permitan dar a conocer los saberes e historias de los pueblos o comunidades nacionales existentes para entender la cocina tradicional en un país multicultural, pluriétnico y biodiverso como el nuestro, es necesario adentrarse en las cocinas regionales y locales. En Colombia entonces, hablamos de nuestras cocinas tradicionales para dar cuenta de esta riqueza (p. 2).

En este sentido, tomando como referente la búsqueda de nuevas alternativas de formación de los profesionales en cocina, la indagación describe las influencias que tiene la región del Caribe en el desarrollo de bebidas. Sin embargo, para poder hablar de ellas es importante resaltar que su elaboración se basa en maíz, arroz y yuca. Por su parte, las bebidas tradicionales son aquellas que vienen posterior a la conquista, con la llegada de la caña de azúcar por parte del señor Pedro de Heredia y, con ella, los cánticos de los esclavos negros y sus costumbres del más antiguo de los continentes. Según la descripción de Leyva (2019), en su obra los tubérculos de origen americano.

Dentro de la fusión de saberes y tradiciones, los españoles introdujeron una fusión de saberes y sabores con la caña llega el azúcar, la panela y, tiempo después, el arte de la destilación. Lo anterior, mezclado con frutas, hierbas y especias que se adentraron en el código genético de los habitantes del territorio. No obstante, estas bebidas han sido tema de estudio a nivel superficial. De allí la dificultad para 
saber de ellas; se conocen porque los individuos que consumen estas bebidas las han experimentado dentro del territorio Caribe, es de consumo frecuente en sus diversos eventos. La investigación se centró en analizar tres (3) categorías: las bebidas fermentadas, las bebidas destiladas y las bebidas sin alcohol.

\section{Metodología}

Mediante el desarrollo etnográfico y experimental del análisis de las bebidas, se estableció una herramienta de recolección de datos: la encuesta. Buscó identificar qué tanto sabían las personas acerca de las bebidas tradicionales y ancestrales de la región Caribe. Posteriormente, inició la recolección de información a través de textos sugeridos, así como una entrevista con la portadora de tradición: la señora Cenilda Urbina. Ella es oriunda de María la baja, un municipio cercano a Sincelejo, en el departamento de Sucre. Relató acerca de las diferentes bebidas preparadas en la casa para festividades, además, hacen parte de su herencia cultural.

\section{Resultados}

Mediante la encuesta realizada sobre el conocimiento de las bebidas ancestrales del Caribe, se puede evidenciar:

Figura 1. Conocimiento de bebidas ancestrales

56 respuestas

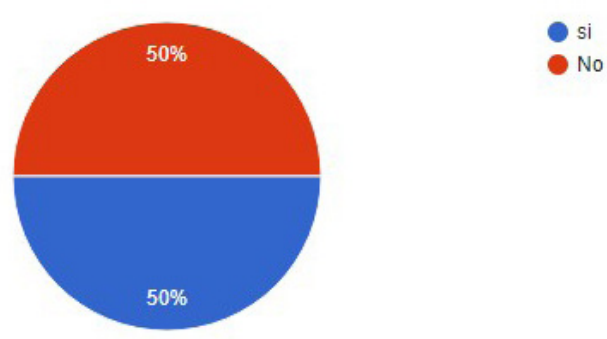

Fuente: elaboración propia. 
Figura 2. Consumo de bebidas ancestrales

56 respuestas
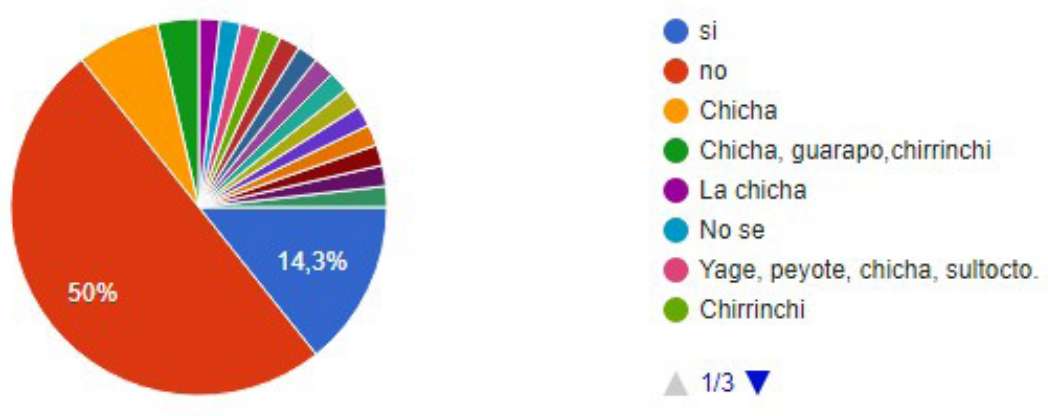

Fuente: elaboración propia.

Según lo expuesto, se evidenció que la mayor parte de personas encuestadas no sabían acerca de las diferentes bebidas ancestrales y tradicionales del Caribe. Muchas de ellas relacionaban que las únicas bebidas ancestrales son la chicha y el guarapo, desconociendo la historia de procedencia de los ingredientes utilizados. En la indagación de consultas de referencias bibliográficas se encontró poca información, resumida de forma básica al desarrollo y preparación, según Caicedo (1984) en su obra El gran libro de la cocina colombiana. Cabe aclarar que solamente seis (6) bebidas son descritas para identificar la región Caribe (se describen varias preparaciones y deja a interpretación del lector la preparación de cada una de ellas). Por otro lado, las bebidas descritas son las siguientes:

\section{Bebidas sin alcohol.}

Una de las primeras en la lista es la chicha, diferente a lo que se piensa no tienen tipo de fermentación alguno, se realizan de todas las frutas disponibles, siendo la chicha de corozo y la chicha de tamarindo las más comunes. Para elaborar las bebidas se pelan las frutas, luego se machacan para elaborar una especie de base, que posteriormente va a ser mezclada con agua, azúcar y hielo.

En el caso del corozo, es una de las frutas más emblemáticas de esta región. Es una especie de "cereza" que se debe cocinar, licuar poco a poco con azúcar, para lograr extraer el sabor y color característico que tiene. Más adelante se le agrega 
hielo y listo: a disfrutar. A partir de estas "chichas" se pueden elaborar los bolis o como los llamaba Cenilda Urbina (2019) en su infancia, los congelados como lo manifestaba.

Figura 3. Preparaciones chicha

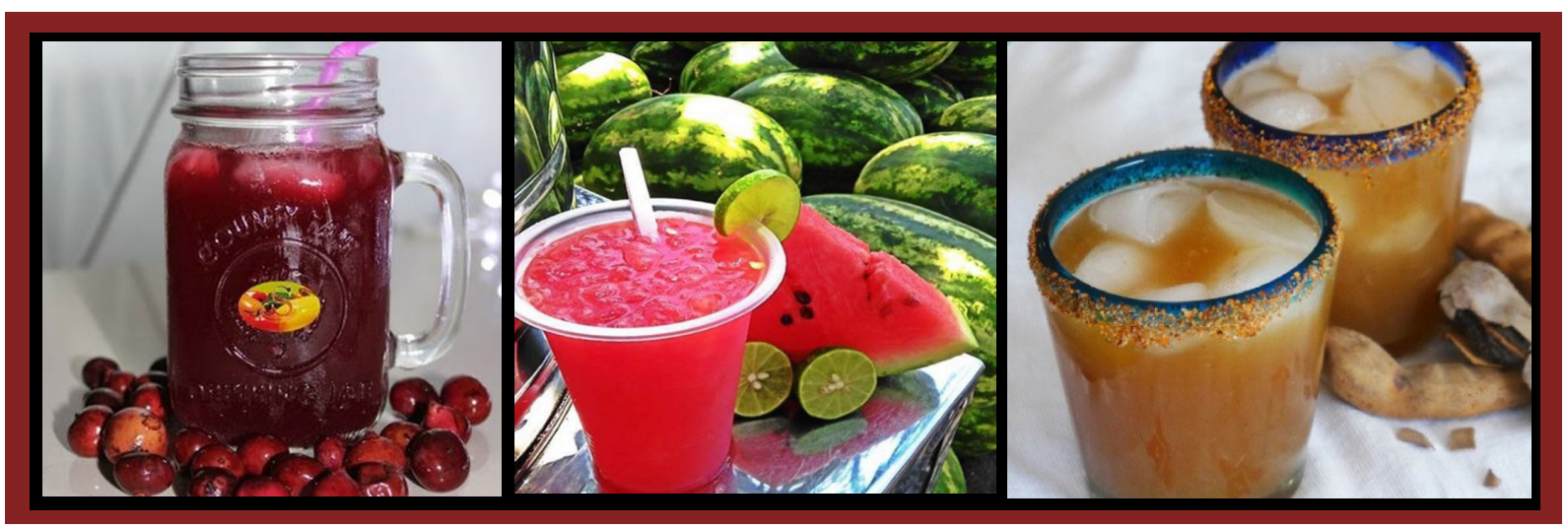

Fuente: elaboración propia.

Luego está el agua de panela con jengibre, muy popular en la tierra de Doña Ceni. También es llamada guarapo costeño en otras partes de la región. Está el café con jengibre, que no es otra cosa sino un tinto infusionado con jengibre. Uno muy popular (por su frescura) es el patillazo: zumo de patilla con limón y hielo.

\section{Bebidas fermentadas.}

Una de las más consumidas es la chicha de arroz (sobre todo en la región de Sucre), tiene una leve fermentación; es muy parecida al masato del interior del país, sin embargo, no es más ligera en cuerpo y cada familia tiene su propia preparación. En esta misma rama está la chicha de yuca endulzada con panela, muy popular en los Montes de María por la abundancia de este producto. Finalmente, no podía faltar la chicha indígena. Según cuenta la historia es una mezcla de masas de maíz y yuca, lo que la hace más fuerte. Además, se encontró la bebida que inspiró una de las canciones más conocidas a lo largo y ancho de nuestro territorio: el "Ron de Vinola", una mezcla de guarapo de piña con uva que se dejaba fermentar en cubas de madera (Ospino, 2016).

Como se mencionó anteriormente, a partir del corozo se generan dos (2) bebidas fermentadas, base fundamental de las tradiciones del Caribe colombiano: la chicha de corozo (con un par de semanas de fermentación) y el vino de corozo 
(el jugo de corozo en botellas de vino que luego se entierran por periodos hasta de dos (2) meses. Tienen un toque acido marcado y un gas carbónico propios del proceso de fermentación. Como dijo doña Ceni, es como la "champaña del pobre", aunque hay que decir que su sabor es muy intenso y se siente una efervescencia agradable en el paladar. Asimismo está el vino de naranja, elaborado con la misma técnica que el vino de corozo (Salazar, 2015).

\section{Bebidas destiladas.}

La costa Caribe fue de las primeras regiones del país en realizar destilados. Una vez llegaron los esclavos negros y trajeron su caña de azúcar, no tardaron en empezar a producir diferentes bebidas para ser comercializadas en las grandes élites y entre las clases populares. En esta última es donde se da a conocer el Ñeque, algo así como el hermano del viche del pacifico. Es un aguardiente con graduación alcohólica variable (depende del productor), de olor muy característico, con notas cítricas y aspecto transparente.

Doña Ceni cuenta que en las ferias y fiestas de su pueblo se hace producción de este licor, fácilmente, con 20.000 pesos se puede tomar durante tres (3) días. La razón: es un licor producido clandestinamente, sin ningún reparo en las normas del Invima. No obstante, sin duda alegra el espíritu de quien lo toma: ácido y fuerte al inicio, pero con un final fresco y licoroso. Asimismo, lo mezclan con jugos para suavizar y se ingiere con limonada de coco.

Claramente al estar en la región Caribe, los rones y su influencia extranjera no se podían pasar por alto. Allí se puede encontrar el ron más tradicional del Caribe y, para muchos, la primera bebida destilada de Colombia: el ron Papare y el ron "no me destape", muy populares en la región de Santa Marta.

Por último, cabe mencionar al chirrinche en la región del magdalena y hacia la Guajira. Es más que una bebida destilada, es ceremonial; estaría en la categoría de ancestral de los destilados colombianos. Es una destilación que luego pasa por procesos de maceración con hierbas y especias propias de la región; en cada "caserío" wayuu tiene un sabor y una característica única. Esta bebida fue explicada por Alfredo Ortiz más conocido como "el cacha". En su museo de chicha tiene parte de la historia de esta emblemática bebida; manifiesta que el chirrinche es la bebida del mestizaje, donde se unen todas las raíces y ha perdurado en el tiempo hasta hoy. 


\section{Conclusiones}

A pesar de no contar con mucho material, y teniendo en cuenta la actual situación del país, no ha sido sencillo realizar un proceso de investigación sobre este tema. Con claridad muestra que no se tiene conocimiento de muchas de las bebidas mencionadas, que merecen ser rescatadas pues son la herencia cultural como nación.

Entonces, se debe apoyar la elaboración de este tipo de productos. Así, a través del conocimiento de normas técnicas, realizar procesos de innovación en la elaboración de las bebidas y documentación. Muchas de estas preparaciones solo las conocen los portadores de tradición y, desafortunadamente, son pocas las personas que tienen interés en esta riqueza, incluso los descendientes de estos portadores ya tienen otros intereses diferentes a la riqueza gastronómica del país.

\section{Referencias}

Agamez, C. (2016). Chicha de yuca. Colombia: El Toque Colombiano

Ajamil, G. (2007). Colombia Amarillo, Azul y Rojo. Bogotá D.C.: Editora Cultural Internacional.

Bracho, D. (2020). 17 delicias que tienes que probar en la Costa Caribe Colombiana. Matador network. Colombia.

Caicedo, C. (2012). Gran libro de la cocina colombiana. Bogotá D.C: Biblioteca Básica de Cocinas Tradicionales de Colombia.

Colombia Patrimonio Cultural. (2020). Región Caribe. Colombia patrimonio cultural. Ministerio de Cultura

Leyva, L. (10 de noviembre de 2019). Arracacha (Arracache). Tuberculos. Recuperado de https://www.tuberculos.org/arracacha/

Ministerio de Cultura. (2013). Política para el conocimiento, la salvaguardia y el fomento de la alimentación y las cocinas tradicionales de Colombia. Bogotá: Ministerio de Cultura. 
Jean Pierre Ríos Rojas

Ospino, R. (22 de abril de 2016). El ron y la cerveza en el Magdalena. Historias del Magdalena. Recuperado de http://historiasdelmagdalena.blogspot. com/2016/04/el-ron-y-la-cerveza-en-el-magdalena.html

Salazar, C. (24 de febrero de 2015). Chicha, bebida ceremonial y milenaria. Ministerio de cultura y patrimonio. Recuperado de https://www. culturaypatrimonio.gob.ec/chicha-bebida-ceremonial-y-milenaria/ 